\title{
Resource supplements cause a change in colony sex-ratio specialization in the mound-building ant, Formica exsecta
}

Received: 22 December 2005 / Revised: 16 March 2006 / Accepted: 24 April 2006 / Published online: 20 May 2006

C) Springer-Verlag 2006

\begin{abstract}
We examine the role of food resources on split sex ratios in Formica exsecta. Models of resource-based sex allocation predict that greater resources will cause an increase in the production of reproductive females (gynes) and an increase in overall size of offspring. We experimentally increased food resources for a subset of colonies in a polygynous population with a very malebiased sex ratio. This increase in food availability caused colonies that were male specialists the prior year to switch to female production. Overall, a significantly greater proportion of food-supplemented colonies produced gynes, compared to control colonies. Moreover, foodsupplemented colonies produced significantly larger workers and males (but not gynes), compared to those produced by control colonies. There was, however, no significant difference in the numerical productivity of food-supplemented and control colonies. We also measured the natural association between colony sex specialization and proximity to conifers, which typically harbor honeydew-bearing aphids (an important natural food source). In line with the view that resources play an important role for determining sex ratios in social insects, we found that female-producing colonies were significantly closer to conifers than were male-producing colonies.
\end{abstract}

Keywords Hymenoptera · Productivity · Resources · Sex allocation $\cdot$ Social insects

Communicated by J. Heinze

W. D. Brown $(\bowtie)$

Department of Biology,

State University of New York at Fredonia,

Fredonia, NY 14063, USA

e-mail: William.Brown@fredonia.edu

L. Keller

Department of Ecology and Evolution, Biophore,

University of Lausanne,

Lausanne 1015, Switzerland

\section{Introduction}

Split sex ratios, i.e., an extreme specialization in the sex of reproductive offspring with some colonies producing mainly males and others mainly females within populations, are one of the most intriguing phenomena in ants and other social Hymenoptera. To date, split sex ratios have been mostly explained on the basis of colony-level variations in kin structure. Relatedness asymmetries cause colony members to have different inclusive fitness gains from rearing male vs female offspring, leading to queen-worker conflict over relative allocation of resources in the two sexes (Trivers and Hare 1976; Charnov 1978; Nonacs 1986a; Pamilo 1991). Because queens are equally related to both sexes of reproductives, their equilibrium investment is expected to equal a 1:1 ratio of the sexes but workers are expected to adjust the sex ratios depending on their relatedness to male vs female brood. When relatedness asymmetries within a colony exceed the population average, workers should specialize on reproductive females (gynes), but when relatedness asymmetries fall below this average, they should specialize on males (Boomsma and Grafen 1990, 1991; Boomsma 1991, 1993; Ratnieks 1991; Bourke and Chan 1994; Ratnieks and Boomsma 1997).

Support for relatedness-induced split sex ratios is mixed, and a growing number of studies suggest that ecological constraints (Deslippe and Savolainen 1995; Aron et al. 1999; Helms 1999; Ode and Rissing 2002; Bono and Herbers 2003; Foitzik et al. 2003) and queen control (Passera et al. 2001; Fournier et al. 2003; Helms et al. 2004; Helms et al. 2005; de Menten et al. 2005) may also play a fundamental role. To date, there have been few experimental tests of hypotheses for split sex ratios in social insects, but evidence supporting a role for food resources comes from a field study in which Deslippe and Savolainen (1995) provided additional food to colonies of the ant Formica podzolica. These colonies allocated a significantly greater proportion of their resources to gynes than did untreated colonies. Similarly, experimental supplements of seeds increased gyne production in the ant 
Aphaenogaster rudis (Morales and Heithaus 1998). Bono and Herbers (2003) showed that Myrmica brevispinosa colonies produced more gynes in response to supplemental sugar but supplemental protein had no effect on sex ratio or productivity. In contrast, Aron et al. (2001) showed that supplemental protein increased proportional investment in sexuals vs workers in the Argentine ant (Linepithema humile), though it did not alter sex ratios. Herbers and Banschbach (1998) found that food supplements shifted sex ratios towards greater production of females in the ant Temnothorax longispinosus, although a previous study had shown the opposite pattern (Backus and Herbers 1992).

A positive relationship between food availability and gyne production is predicted by a pair of models of sexratio variation that focus on resources, rather than relatedness, as the causal variables of sex-ratio variation. First, the queen-replenishment hypothesis (Brown and Keller 2000; Brown et al. 2002) holds that gyne production depends on resources available per queen in species with polygynous (multiple-queen) colonies. According to the queen-replenishment hypothesis, related female offspring compete for opportunities to reproduce within the natal colony, a phenomenon known as local resource competition. However, the intensity of local resource competition within the natal colony will decrease as the abundance of resource grows and at some point colonies will benefit from gaining additional reproductive queens. Thus, only colonies with excess resources per queen will produce females. Colonies with a shortage of resources per queen will specialize on male production and we generally predict a male-biased population sex ratio. Second, the hypothesis of multifaceted parental investment (MFPI) (Rosenheim et al. 1996) also predicts that greater resources will spur female production. MFPI holds that, because gynes are large and especially costly to produce, their production may often be constrained by a lack of sufficient resources available to the colony. Therefore, when resources are scarce, diploid offspring are channeled into becoming workers rather than reproductives, while males still develop into sexual adults; when resources are abundant, colonies specialize on production of gynes (Nonacs 1986a,b; Rosenheim et al. 1996).

In this study, we provide an experimental test of the relationship between food availability and sex ratio by altering the pool of food resources available to individual colonies of polygynous Formica exsecta and measuring sex-ratio specialization. Although the vast majority of colonies produce only male sexuals in polygynous $F$. exsecta and the population sex ratio is typically very male biased (Brown and Keller 2000; Brown and Keller 2002; Liautard et al. 2003), we predict that food supplements will stimulate a switch from male production before feeding to female production afterwards. Because aphid honeydew is an important natural food resource for this species and many other Formica species, we also examine the relationship between colony sex specialization and proximity to potentially aphid-bearing conifers.

\section{Materials and methods}

We studied a population of polygynous $F$. exsecta located at Les Chenevières, a pasture at approximately $1,200 \mathrm{~m}$ in the commune of Le Vaud in the Jura Mountains of Switzerland. This population has been the subject of several previous studies (Brown and Keller 2000; Keller et al. 2001; Brown and Keller 2002; Brown et al. 2002; Liautard and Keller 2001; Brown et al. 2003). The study population contains more than 1,200 nests (Liautard et al. 2003) with high year-to-year survivorship and is characterized by a moderate level of polygyny, with a median value of about six queens per colony based on genetic measures of effective queen number (Brown and Keller 2000). These colonies had been previously mapped and marked with a unique alphanumerical code written onto a wooden stake that was driven into the ground immediately adjacent to the nest.

\section{Food supplements}

The experiments began when workers resumed foraging in spring, immediately after snow-melt (ca. April 1). From previous work, we had knowledge of the sex-ratio specialization of each colony during the earlier breeding season. We selected 39 previously male-producing colonies and 21 previously female-producing colonies. We included a greater number of male-producing colonies because they are much more numerous and because we were primarily testing the ability of food supplements to cause a shift from male to female production. We supplemented resources (food-plus treatment) for 30, randomly chosen colonies and left the remaining 30 colonies as unmanipulated controls. Food supplementation was conducted by placing tuna (a protein source) and honey (a sugar source) on or immediately adjacent to the nest every third day beginning in the spring and continuing until sexual brood became pupae (late June). Sugar and protein sources were distributed ad libitum and separately into 9-cm plastic Petri dishes. Approximately $100 \mathrm{~g}$ of honey and $30 \mathrm{~g}$ of tuna were provided once every 3 days. We estimate that an approximate total of $3 \mathrm{~kg}$ of honey and $1 \mathrm{~kg}$ of tuna were provided per treatment colony over the entire breeding season. Most, but not all, of the food supplements were usually consumed during this period, suggesting that we had satiated the colonies with these particular nutrients. Large Formica aquilonia colonies of about one million workers consume approximately $200 \mathrm{~kg}$ of sugar per season (Rosengren and Sundström 1987, 1991). Assuming that $F$. exsecta require similar amounts per worker and given that $F$. exsecta colonies contain between 5,000 and 25,000 workers (Brown et al. 2002), we estimated that colonies should require from 1 to $5 \mathrm{~kg}$ of sugar during the period of sexual production. Thus, our treatment should have come very close to meeting the maximum requirements of sugar and protein. 
For each focal colony, we estimated the investment in males, gynes, and workers by using the mark-recapture method of Sundström (1995). The vast majority of sexuals are produced from the first eggs laid during the season. Once most larvae had entered the pupal stage, but before any had emerged as adults, nests were gently opened and between 20 and 3,980 pupae per colony were collected from just beneath the surface. A total of 63,309 pupae were individually marked with a dot of ink from a nontoxic, permanent red marker (Sharpie). Pupae were released back into the nest by gently opening the surface, returning the marked pupae, and closing the nest. Workers continuously move pupae within the nest (presumably to locations of optimum temperature and humidity) and effectively mix the brood. Two days later, we captured another sample of pupae and used the proportion of marked to unmarked pupae to estimate the total number of pupae within the colony.

Colony sex specialization and progeny production

We also collected 10-150 pupae per colony to estimate the ratio of workers, gynes, and males. Progeny sex and caste were estimated by moistening pupae in ethanol and observing the size, eye shape, and genitalia of late-stage pupa. Males of $F$. exsecta are size-dimorphic (Agosti and Hauschteck-Jungen 1987, Fortelius et al. 1987) and pupae fall into three nearly discrete size categories corresponding to workers, small males, and the combination of large males and gynes. Male pupae were classified as large if their size was identical to that of the gynes. Otherwise, they were counted as small males. Large males are generally produced in female-producing colonies, whereas small males are produced within both male- and femaleproducing colonies. As in previous studies (Brown and Keller 2000; Brown et al. 2002; Liautard et al. 2003), we classified colonies as male producing if they produced no gynes and female-producing if they produced gynes, usually along with large and small male progeny.

To determine dry weights, we collected adult males and gynes (up to 10 individuals per sex and morphotype per nest) before flight as they emerged from their nest. Young workers were obtained by collecting worker pupae from each colony and placing them in laboratory nests with ca. 50 adult workers and a small amount of nest material. New workers were easily identified as callow, tan-colored individuals and were collected within $24 \mathrm{~h}$ after eclosion from the pupae. All individuals were dried at $60^{\circ} \mathrm{C}$ for $24 \mathrm{~h}$, and weighed on a MT5 Mettler balance accurate to 0.01 mg.

\section{Colony size}

We estimated the size of the worker force using the protocol for worker mark-recapture outlined by Sundström (1995) and Brown et al. (2002). Before brood emerged, 200 to 2,000 adult workers per colony were collected, counted, sprayed lightly with a leather and wood spray paint, and released back onto the nest. Approximately $24 \mathrm{~h}$ later, workers were recaptured on the nest and the total number of workers was estimated from the proportion of marked to unmarked ants.

\section{Experimental analyses}

Colony size and numerical production of progeny were normalized (Kolmogorov-Smirnov test, Lilliefors $P>0.05$ ) by $\ln$ transformation before analyses. Relative worker production was transformed by the arcsine of the square root. Means were backtransformed and are reported with backtransformed $95 \%$ confidence intervals.

Supplemental food may affect any of three components of overall brood production: (1) total number of progeny (numerical productivity), (2) caste ratios (including sex ratios), or (3) individual sizes within castes. Because MFPI and the queen-replenishment hypotheses make specific predictions about how resources will alter productivity, we tested each of these three effects separately. We used ANCOVA to analyze the effect of treatment on numerical brood production, using food supplementation vs control as a fixed factor and colony size as a covariate.

Next, we analyzed the consequences of food treatments on colony sex ratios using two analyses. First, we analyzed frequencies at which colonies switched their sex-ratio specialization in response to food supplements, predicting that food-supplemented colonies would be more likely to switch from male-producing to female-producing because of the added resources per queen. Second, we compared the proportion of female-producing colonies between treatment and control groups, using logistic regression with colony size (worker number) and productivity as covariates. We also tested the effect of food supplements on proportional allocation to workers. Four colonies (three controls and one treatment) produced no sexual brood and are excluded from sex-ratio analyses.

Finally, we analyzed the effect of treatment on the dry mass of individual progeny using a nested ANOVA, within individual dry mass as the dependent variable and colony identity as a factor nested within treatment.

\section{Sex specialization and proximity to conifers}

Because conifers tend to harbor aphids that produce honeydew, a major food source for Formica species, we tested the prediction that colonies situated closer to conifers would have a greater resource base and, thus, would be more likely to specialize on female sexual progeny. To test this prediction, we recorded sex specialization by opening nests and recording the presence or absence of gyne pupae and we then measured the distance from the edge of colony dome to the nearest conifer using a 50-m measuring tape. We collected these data for a total of 162 colonies in six populations within pastures in the Swiss Jura Mountains, 
including Le Bois de Gaye, La Comb aux Rocs, Les Orgères, Le Pré de Joux, Le Pré Nouveau, and nonexperimental colonies in the population at Les Chenevières (see Liautard et al. 2003 for information about these populations).

\section{Results}

Effect of food supplements on sex specialization and worker production

Food supplements had a significant effect of the direction in which sex ratios changed between years. Specifically, supplemental feeding increased the rate at which colonies switched to female production if the colony was originally male-producing $\left(\chi^{2}=5.61, d f=1, P<0.05\right) ; 12$ of $20(60 \%)$ food-supplemented colonies switched to female production, compared to only 3 of $15(20 \%)$ of control colonies. Supplemental feeding increased the rate at which colonies remained female-producing, though not significantly so (Fisher's exact test, $P>0.05$ ); four of seven $(57 \%)$ foodsupplemented colonies remained as female producing, compared to 4 of 14 (29\%) control colonies.

Similarly, within the year of the experiment, food supplements resulted in a significantly greater proportion of female-producing colonies $\left(\chi^{2}=7.14, d f=1, P<0.01\right)$. Overall, 16 of 27 (59\%) food-supplemented colonies produced females whereas only 7 of 29 (24\%) control colonies produced females. Female-producing colonies were also significantly larger (Wald $=5.59, d f=1, P=0.02$ ).

As we have shown previously (Brown et al. 2002), maleproducing colonies produced significantly more workers than female-producing colonies $\left(F_{1,52}=22.28, P<0.0005\right)$. However, there was no significant independent effect of food supplements on worker production $\left(F_{1,52}=2.06\right.$, $P=0.16$ ). Only female-producing colonies produced large males, but within female-producing colonies, there was no effect of food supplements on numerical investment in large males $(t=0.95, d f=19, P=0.10)$.

Effect of food supplements on progeny number and size

Colony size had a strong positive effect on numerical productivity $\left(F_{1,52}=12.41, P<0.001\right)$ but food supplements did not significantly affect the total number of progeny produced (ANOVA $F_{1,52}=0.05, P=0.82$ ). The average (backtransformed) numerical productivity was 14,052 $(95 \%$ CI $6,495-30,387)$ brood in control colonies and $13,899(95 \%$ CI $5,996-32,220)$ brood in treatment colonies.

Although total numbers of progeny were equivalent, colonies receiving food supplements tended to produce significantly larger progeny. As reported above, a higher proportion of females were gynes in food-supplemented colonies and gynes weighed more than 3.5 times workers (Table 1). Moreover, sizes of both workers and small males were significantly larger in food-supplemented colonies, compared to controls. By contrast, there was no significant effect of food supplementation on the weight of the large males and gynes.

Sex specialization and proximity to conifers

Across the 162 colonies in six populations in the Swiss Jura Mountains, female-producing colonies were significantly closer (mean $8.76 \mathrm{~m} ; 95 \%$ CI $6.67-11.51 \mathrm{~m}$ ) to a coniferous tree than were male-producing colonies (mean $20.01 \mathrm{~m} ; 95 \% \quad$ CI $17.71-22.62 \mathrm{~m}) \quad\left(F_{1,152}=41.62\right.$, $P<0.0001)$. However, this effect varied among populations as indicated by a significant interaction between population and sex-ratio specialization $\left(F_{4,152}=2.82, P=0.0002\right)$. The effect was strongest in colonies with a low average distance to aphid-bearing conifers (including Les Chenevières, our main study population). Thus, it appears that when trees are nearby, they have a substantial impact on colony sex ratios. When these food sources are not in close proximity, the proportion of female-producing colonies is comparable but aphid honeydew is unlikely to explain sex ratios.

\section{Discussion}

Supplemental food significantly altered sex ratios, with colonies receiving additional sugar and protein being more likely to specialize on female sexual progeny. Moreover, colonies that had specialized on male production the previous year were more likely to switch to female production when given supplementary food. These results give strong experimental support to models of resourcebased split sex ratios.

Table 1 Comparisons of individual, dry body mass for gynes, large males, small males, and workers produced by food supplemented and control colonies of Formica exsecta

\begin{tabular}{|c|c|c|c|c|c|c|c|}
\hline & \multicolumn{2}{|c|}{ Food supplemented } & \multicolumn{2}{|l|}{ Control } & \multirow[t]{2}{*}{$F$} & \multirow[t]{2}{*}{$d f$} & \multirow[t]{2}{*}{$P$} \\
\hline & Body mass (g) & $95 \% \mathrm{CI}$ & Body mass (g) & $95 \% \mathrm{CI}$ & & & \\
\hline Gynes & 4.34 & $4.26-4.42$ & 4.49 & $4.38-4.60$ & 2.40 & 1,138 & 0.14 \\
\hline Large males & 3.61 & $3.46-3.76$ & 3.45 & $3.32-3.58$ & 1.20 & 1,81 & 0.28 \\
\hline Small males & 1.87 & $1.82-1.92$ & 1.79 & $1.74-1.84$ & 4.27 & 1,355 & 0.040 \\
\hline Workers & 1.21 & $1.18-1.24$ & 1.16 & $1.11-1.19$ & 28.89 & 1,365 & $<0.0005$ \\
\hline
\end{tabular}


Our results are in sharp contrast with those of Aron et al. (2001), who reported that protein supplementation in captive colonies of the Argentine ant, Linepithema humile, caused a numerical increase in brood production but did not alter sex ratios. In our study, supplemental food caused a shift in sex ratios but no significant change in numerical progeny production. Instead, there was a shift towards the production of larger castes (gynes and large males) and greater investment in individual workers and small males. Our results are more consistent with those of Deslippe and Savolainen (1995), Morales and Heithaus (1998), and Bono and Herbers (2003), each of which reported greater female-biased production under food supplements. However, in the ant Aphaenogaster rudis, the difference in sex ratio was apparently due to greater numerical production of gynes without any change in worker or male production (Morales and Heithaus 1998). In Myrmica brevispinosa, greater female production occurred in colonies receiving supplemental sucrose but not those receiving only supplemental protein (Bono and Herbers 2003), suggesting that the nutritional quality of the resource has an important effect on sex ratios.

The two models of resource-based sex ratios, queenreplenishment and multifaceted parental investment (MFPI), are not mutually exclusive and our results support general predictions of each model. Both suggest that a greater resource pool will simulate production of female sexual progeny. According to queen-replenishment hypothesis, this occurs because the colony can support more reproductive queens, and, thus, the colony produces females to bolster its cadre of related queens (Brown and Keller 2000). Our previous studies have provided particularly strong support of queen replenishment. Female progeny production corresponds to a low effective queen number and high per capita queen productivity (Brown and Keller 2000; Brown et al. 2002; Kümmerli et al. 2005). Daughters appear to be adopted back into their natal colonies (Liautard and Keller 2001) and female production is followed by an increase in effective queen number and a switch to specialization of males the following breeding season (Brown and Keller 2002).

However, our results also provide support for MFPI. According to MFPI, greater female production occurs when progeny numbers are constrained by something other than the immediate availability of resources required for progeny growth, and, thus, excess resources can be channeled into producing larger individual progeny (notably gynes) without much additional cost (Rosenheim et al. 1996). Gilboa and Nonacs (2006) supported MFPI in three ant species, Formica hewitti, F. planipilis, and Pogonomyrmex salinus, based on the body size distribution of male and female progeny. In our study, the overall increase in progeny production within food-supplemented colonies was mediated through changes in progeny size, including discrete changes in caste and increases in worker and small male mass, and not through changes in the number of total progeny. A lack of change in numerical productivity could arise for either of two reasons. First, numerical production may be constrained by another resource that we did not manipulate during the experiment (Rosenheim et al. 1996). Second, the initial investment that determined progeny numbers in the cohort that we censused may have been determined before the beginning of our food supplements. If so, additional resources could only be used to increase the sizes and developmental trajectories of a number of offspring that was fixed very early in the breeding season. Although we initiated the treatment as early as possible in the spring, it is possible that queens and workers utilize resources acquired before overwintering for initial investment in progeny. In contrast to our results, Herbers and Banschbach (1998) reported that greater gyne production in food-supplemented plots of Temnothorax longispinosus was associated with numerical increases in progeny production, including a 20-fold increase in gyne production, but no significant increase in dry mass of individual progeny. However, their food supplements covered two sequential breeding seasons, and, thus, they were certain to be providing resources before the onset of progeny production in the second year. Ode and Rissing (2002) showed that the timing of food supplementation has important consequences for sex allocation in Messor pergandei. Early food supplements while queens were laying reproductive brood increased the number of gynes, whereas later food supplements increased gyne size.

In our experiment, food supplements increased the sizes of worker and male brood, but not the size of gynes. Larger males have greater fitness in harvester ants due to greater mating success and greater sperm production (Abell et al. 1999; Wiernasz et al. 2001) and similar directional selection on male body size may occur in $F$. exsecta. Lack of an effect of food supplements on gyne size is surprising, given that larger queens might be expected to have greater success at becoming established as reproductives. For example, Wiernasz and Cole (2003) showed that larger queen Pogonomrymex occidentalis have greater success at colony founding. Perhaps directional selection on gyne size is reduced in species in polygynous species that reproduce by colony budding rather than independent colony founding, such as polygynous $F$. exsecta.

In addition to the effect of food supplements on sex ratios, we found a strong association between femaleproduction and proximity to conifers, and by extension, proximity to aphid honeydew, a major natural food source for mound-building Formica ants. Boomsma (1993) suggested that ants in aphid-rich nest sites should specialize on gynes because the high carbohydrate availability (in the form of honeydew) will make gynes relatively cheap to produce. Average distance of femaleproducing colonies to conifers in $F$. exsecta was less than half that of male-producing colonies. These results match those of Deslippe and Savolainen (1995), who reported that sex ratios were more female-biased in colonies of F. podzolica along forest edges. In our study, the exception was a single population (Le Pré Nouveau) that was situated in a large and unusually open meadow with a very large average distance to conifers ( $30.38 \mathrm{~m}$ compared to between 6.92 and $24.38 \mathrm{~m}$ among the other populations). This population contained a remarkably high proportion of 
female-producing colonies (12 of 23 surveyed (52\%) for an ant that typically has strongly male-biased sex ratios (Brown and Keller 2000; Liautard et al. 2003). However, in this population, there was no difference in proximity of male- and female-producing colonies to conifers. We presume that progeny production at Pré Nouveau was based predominantly on resources other than honeydew from aphid-dwelling conifers.

$F$. exsecta is a model species for studies of sex-ratio evolution (Pamilo and Rosengren 1983; Sundström et al. 1996; Brown and Keller 2000; Brown et al. 2002; Liautard et al. 2003; Kümmerli et al. 2005). We have shown that sex ratios in wild populations correlate with proximity to natural food sources and are altered by experimental changes food availability. Our results demonstrate the important role of food resources in determining the sex ratios in this polygynous social insect.

Acknowledgements We thank our numerous helpers for their efforts in the field and the Swiss NSF for financial support.

\section{References}

Abell AJ, Cole BJ, Reyes R, Wiernasz DC (1999) Sexual selection on body size and shape in the western harvester ant, Pogonomyrmex occidentalis Cresson. Evolution 53:535-545

Agosti D, Hauschteck-Jungen E (1987) Polymorphism of males in Formica exsecta Nyl. (Hym. Formicidae). Insectes Soc 34:280-290

Aron S, Campan E, Boomsma JJ, Passera L (1999) Social structure and split sex ratios in the ant Pheidole pallidula. Ethol Ecol Evol 11:209-227

Aron S, Keller L, Passera L (2001) Role of resource availability on sex, caste and reproductive allocation ratios in the Argentine ant Linepithema humile. J Anim Ecol 70:831-839

Backus VL, Herbers JM (1992) Sexual allocation ratios in forest ants: food limitation does not explain observed patterns. Behav Ecol Sociobiol 30:249-425

Bono JM, Herbers JM (2003) Proximate and ultimate control of sex ratios in Myrmica brevispinosa colonies. Proc R Soc Lond B 270:811-817

Boomsma JJ (1991) Adaptive colony sex ratios in primitively eusocial bees. Trends Ecol Evol 6:92-95

Boomsma JJ (1993) Sex ratio variation in polygynous ants. In: Keller L (ed) Queen number and sociality in insects. Oxford University Press, Oxford, pp 86-109

Boomsma JJ, Grafen A (1990) Intraspecific variation in ant sex ratios and the Trivers-Hare hypothesis. Evolution 44:1026-1034

Boomsma JJ, Grafen A (1991) Colony-level sex ratio selection in the eusocial Hymenoptera. J Evol Biol 3:383-407

Bourke AFG, Chan GL (1994) Split sex ratios in ants with multiple mating. Trends Ecol Evol 9:120-122

Brown WD, Keller L (2000) Colony sex ratios vary with queen number but not relatedness asymmetry in the ant Formica exsecta. Proc R Soc Lond B 267:1751-1757

Brown WD, Keller L (2002) Queen recruitment and split sex ratios in polygynous colonies of the ant Formica exsecta. Ecol Lett 2:102-109

Brown WD, Keller L, Sundström L (2002) Sex allocation in moundbuilding ants: the roles resources and queen replenishment. Ecology 83:1945-1952

Brown WD, Liautard C, Keller L (2003) Sex-ratio dependent execution of queens in the ant, Formica exsecta. Oecologia 134:12-17
Charnov EL (1978) Evolution of eusocial behavior: offspring choice or parental parasitism. J Theor Biol 75:451-465

de Menten L, Fournier D, Brent C, Passera L, Vargo EL, Aron S (2005) Dual mechanism of queen influence over sex ratio in the ant Pheidole pallidula. Behav Ecol Sociobiol 58:527-533

Deslippe RJ, Savolainen R (1995) Sex investment in a social insect: the proximate role of food. Ecology 76:375-382

Foitzik S, Strätz M, Heinze J (2003) Ecology, life history and resource allocation in the ant, Leptothorax nylanderi. J Evol Biol 16:670-680

Fortelius W, Pamilo P, Sundström L (1987) Male size dimorphism and alternative tactics in Formica exsecta ants (Hymenoptera, Formicidae). Ann Zool Fenn 24:45-54

Fournier D, Keller L, Passera L, Aron S (2003) Colony sex ratios vary with breeding system but not relatedness asymmetry in the facultatively polygynous ant Pheidole pallidula. Evolution 57:1336-1342

Gilboa S, Nonacs P (2006) Testing models of parental investment strategy and offspring size in ants. Oecologia 146:667-674

Helms KR (1999) Colony sex ratios, conflict between queens and workers, and apparent queen control in the ant Pheidole desertorum. Evolution 53:1470-1478

Helms KR, Fournier D, Keller L, Passera L, Aron S (2004) Colony sex ratios in the facultatively polygynous ant Pheidole pallidula: a reanalysis with new data. Evolution 58:1141-1142

Helms KR, Reuter M, Keller L (2005) Sex-ratio conflict between queens and workers in eusocial Hymenoptera: mechanisms, costs, and the evolution of split colony sex ratios. Evolution 59:2626-2638

Herbers JM, Banschbach VS (1998) Food supply and reproductive allocation in forest ants: repeated experiments give different results. Oikos 83:145-151

Keller L, Liautard C, Reuter M, Brown WD, Chapuisat M, Sundström L (2001) Sex ratio and Wolbachia infection in the ant Formica exsecta. Heredity 87:227-233

Kümmerli R, Helms KR, Keller L (2005) Experimental manipulation of queen number affects colony sex ratio investment in the highly polygynous ant Formica exsecta. Proc R Soc Lond B 272:1789-1794

Liautard C, Keller L (2001) Restricted effective queen dispersal at a microgeographic scale in polygynous populations of the ant Formica exsecta. Evolution 55:2484-2492

Liautard C, Brown WD, Helms KR, Keller L (2003) Temporal and spatial variations of gyne production in the ant Formica exsecta. Oecologia 136:558-564

Morales MA, Heithaus ER (1998) Food from seed-dispersal mutualism shifts sex ratios in colonies of the ant Aphaenogaster rudis. Ecology 79:734-739

Nonacs P (1986a) Ant reproductive strategies and sex allocation theory. Quart Rev Biol 61:1-21

Nonacs P (1986b) Sex ratio determination within colonies of ants. Evolution 40:199-204

Ode PJ, Rissing SW (2002) Resource abundance and sex allocation by queen and workers in the harvester ant, Messor pergandei. Behav Ecol Sociobiol 51:548-556

Pamilo P (1991) Evolution of colony characteristics in social insects. 1. Sex allocation. Amer Natur 137:83-107

Pamilo P, Rosengren R (1983) Sex ratio strategies in Formica ants. Oikos 40:24-35

Passera L, Aron S, Vargo EL, Keller L (2001) Queen control of sex ratio in fire ants. Science 293:1308-1310

Ratnieks FLW (1991) Facultative sex allocation biasing by workers in social Hymenoptera. Evolution 45:281-292

Ratnieks FLW, Boomsma JJ (1997) On the robustness of split sex ratio predictions in social Hymenoptera. J Theor Biol 185: 423-439

Rosengren R, Sundström L (1987) The foraging system of a red wood ant colony (Formica s.str.). In: Pasteels JM, Deneubourg $\mathrm{JL}$ (eds) From individual to collective behaviour in social insects. Experientia (Suppl 54):117-138 
Rosengren R, Sundström L (1991) The interaction between red wood ants Cinara aphids and pines - a ghost of a mutualism past? In: Cutler DF, Huxley CR (eds) Interaction between ants and plants. Oxford University Press, Oxford, pp 80-92

Rosenheim JA, Nonacs P, Mangel M (1996) Sex ratios and multifaceted parental investment. Amer Natur 148:501-535

Sundström L (1995) Sex allocation and colony maintenance in monogyne and polygyne colonies of Formica truncorum (Hymenoptera: Formicidae): the impact of kinship and mating structure. Amer Natur 146:182-201
Sundström L, Chapuisat M, Keller L (1996) Conditional manipulation of sex ratios by ant workers: a test of kin selection theory. Science 274:993-994

Trivers RL, Hare H (1976) Haplodiploidy and the evolution of the social insects. Science 191:249-263

Wiernasz DC, Cole BJ (2003) Queen size mediates queen survival and colony fitness in harvester ants. Evolution 57:2179-2183

Wiernasz DC, Sate AK, Abell AJ, Cole BJ (2001) Male size, sperm transfer, and colony fitness in the western harvester ant, Pogonomyrmex occidentalis. Evolution 55:324-329 